\title{
Wood Identification of Historical Architecture in Korea by Synchrotron X-ray Microtomography-Based Three-Dimensional Microstructural Imaging $^{1}$
}

\author{
Sung-Wook $\mathrm{HWANG}^{2} \cdot$ Suyako TAZURU² ${ }^{2}$ Junji SUGIYAMA (D) ${ }^{2,3, \dagger}$
}

\begin{abstract}
For visual inspection-based wood identification, optical microscopy techniques typically require a relatively large sample size, and a scanning electron microscope requires a clean surface. These novel techniques experience limitations for objects with highly limited sampling capabilities such as important and registered wooden cultural properties. Synchrotron X-ray microtomography (SR- $\mu \mathrm{CT}$ ) has been suggested as an effective alternative to avoid such limitations and various other imaging issues. In this study, four pieces of wood fragments from wooden members used in the Manseru pavilion of Bongjeongsa temple in Andong, Korea, wereused for identification. Three-dimensional microstructural images were reconstructed from these small wood samples using SR- $\mu$ CT at SPring-8. From the analysis of the reconstructed images, the samples were identified as Zelkova serrata, Quercus sect. Cerris, and Pinus koraiensis. The images displayed sufficient spatial resolution to clearly observe the anatomical features of each species. In addition, the three-dimensional imaging allowed unlimited image processing.
\end{abstract}

Keywords: manseru pavilion, bongjeongsa temple, cultural property, synchrotron x-ray microtomography, wood identification

\section{INTRODUCTION}

Studies on wooden cultural properties begin with accurate wood identification. The reason is that wood itself is not only a record of various climate and environmental changes, but can also provide information to predict vegetation, social, cultural and trade relations of the past. General wood identification is performed by visual inspection of various wood tissues based on established wood anatomy (Eom and Park, 2018, Park et al., 2018; Lee et al., 2018). Although visual inspection is the most reliable method, there are practical limitations when sampling is extremely limited, such as for important wooden cultural properties.

Computed tomography (CT) is a non-destructive imaging technique that visualizes the internal threedimensional structure of wood by projecting X-rays to an object at various angles and reconstructing the absorption difference through mathematical methods using a computer. However, conventional CT imaging has failed to provide images by which anatomical characteristics can be observed from wood owing to

\footnotetext{
${ }_{1}^{1}$ Date Received February 21, 2020, Date Accepted April 13, 2020

${ }^{2}$ Research Institute for Sustainable Humanosphere, Kyoto University, Uji, Kyoto 611-0011, Japan

${ }^{3}$ College of Materials Science and Engineering, Nanjing Forestry University, Nanjing 210037, China

$\dagger$ Corresponding author: Junji SUGIYAMA (e-mail: sugiyama.junji.6m@kyoto-u.ac.jp, ORCID: 0000-0002-5388-4925)
} 
its low spatial resolution. Computer vision-based methods should be used to identify wood species using CT images (Kobayashi et al., 2015, 2019a). Synchrotron $\mathrm{X}$-ray microtomography $(\mathrm{SR}-\mu \mathrm{CT})$ combines the synchrotron X-ray micro-imaging with $\mathrm{CT}$ techniques and provides a spatial resolution of tens of nanometers to micrometers to visualize the structure inside a tiny object. SR- $\mu \mathrm{CT}$ has been considered as an alternative to the conventional method owing to the limiting of the wood sample size (Steppe et al., 2004; Van den Bulcke et al., 2009; Mizuno et al., 2010; Tazuru and Sugiyama, 2019).

This study presents three-dimensional microstructural images of small samples taken from Manseru pavilion in Bongjeongsa temple by SR- $\mu \mathrm{CT}$ and reports the identification results.

\section{EXPERIMENTAL}

\subsection{Wood samples}

Four wood fragments collected from wooden members used in Manseru pavilion of Bongjeongsa temple, Andong, Korea, were provided from the Korea Forestry Promotion Institute in 2017. Manseru, the pavilion and main gate of Bongjeongsa temple, was built in 1680 and is designated as a tangible cultural property of Gyeongsangbuk-do Province. Moreover, Bongjeongsa temple is one of the seven South Korean Buddhist temples listed as a UNESCO World Heritage Site in
2018 under the name Sansa, Buddhist mountain monasteries in Korea. The samples were taken from the first two columns on the left side of the ground floor and from a beam and a joist on the second floor. The samples were tiny with a thin and long shape, ranging in size from a minimum of $2.2 \times 1.7 \times 7.2 \mathrm{~mm}$ $(\mathrm{R} \times \mathrm{T} \times \mathrm{L})$ to a maximum of $1.4 \times 5.8 \times 13.4 \mathrm{~mm}$.

\subsection{Synchrotron $X$-ray microtomography}

To obtain three-dimensional microstructural images from the samples, the SR- $\mu \mathrm{CT}$ scan was performed on the beamline 20XU at SPring-8, Hyogo Prefecture, Japan. The synchrotron is a large ring-shaped electron accelerator, and electrons can achieve energies of several $\mathrm{GeV}$. When electrons are forced to move out of their orbit by deflecting or bending magnets, they emit a synchrotron X-ray (Casali, 2006; Creagh, 2007). Three-dimensional imaging can be performed through computed tomography using the synchrotron X-ray. The beamline $20 \mathrm{XU}$ is designed to apply various imaging technologies such as microtomography, X-ray microscopy, and medical imaging. For a detailed technical description of this beamline, see the article by Suzuki et al. (2004).

Wood samples were cut and trimmed into a cylindrical shape with 5-mm height and $0.7-\mathrm{mm}$ diameter and then fixed to a specially designed support stick for scanning. Two specimens from each sample, a total of eight specimens, were prepared. The mounted specimen was scanned with a stepwise rotation of 0.1 degree, and
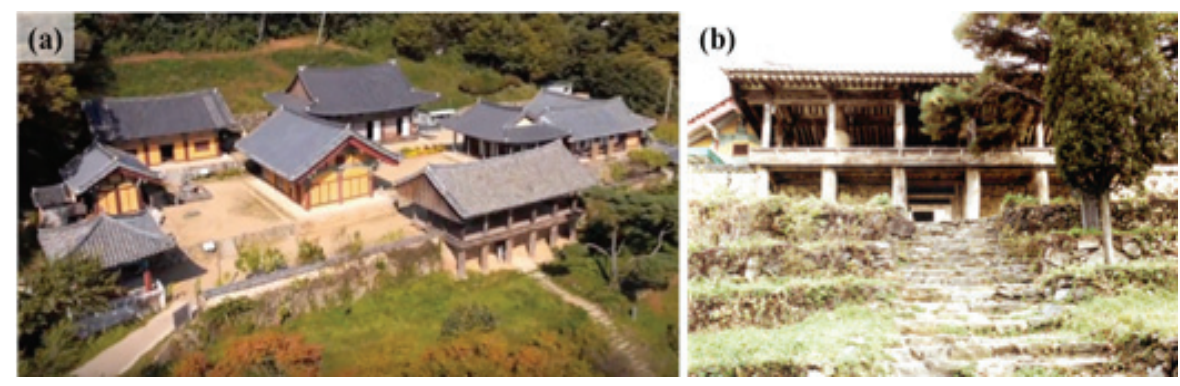

Fig. 1. Bongjeongsa temple (a) and its gatehouse, Manseru pavilion (b). 
Wood Identification of Historical Architecture in Korea by Synchrotron X-ray Microtomography-Based Three-Dimensional Microstructural Imaging

a total of 1800 projections were acquired by a CCD camera coupled with an optical lens. The size and resolution of the acquired images were $2048 \times 2048$ pixels and $0.472 \mu \mathrm{m} /$ pixel, respectively. Then, 2048 slide images were reconstituted by an in-house developed software program 'CT'.

\subsection{Visualization and analysis of images}

The images were visualized and analyzed using the software VGStudio MAX 2.2 (Volume Graphics GmbH, Germany). The 2048 two-dimensional images for each sample were reconstructed to generate a three-dimensional image. The software allows for free cutting of the images, that is, it can observe all sections required by the user. Wood identification was carried out on the basis of the anatomical characteristics obtained by observing three orthogonal sections. All the reconstructed images were preprocessed with a median filter to remove noise.

\section{RESULTS and DISCUSSION}

Three-dimensional microstructural images of the four wood samples were obtained by SR- $\mu$ CT with image reconstruction software. The images were clear enough to distinctly observe the anatomical characteristics present in the reconstructed area.

\subsection{Columns}

Fig. 2 presents reconstructed images of the wood
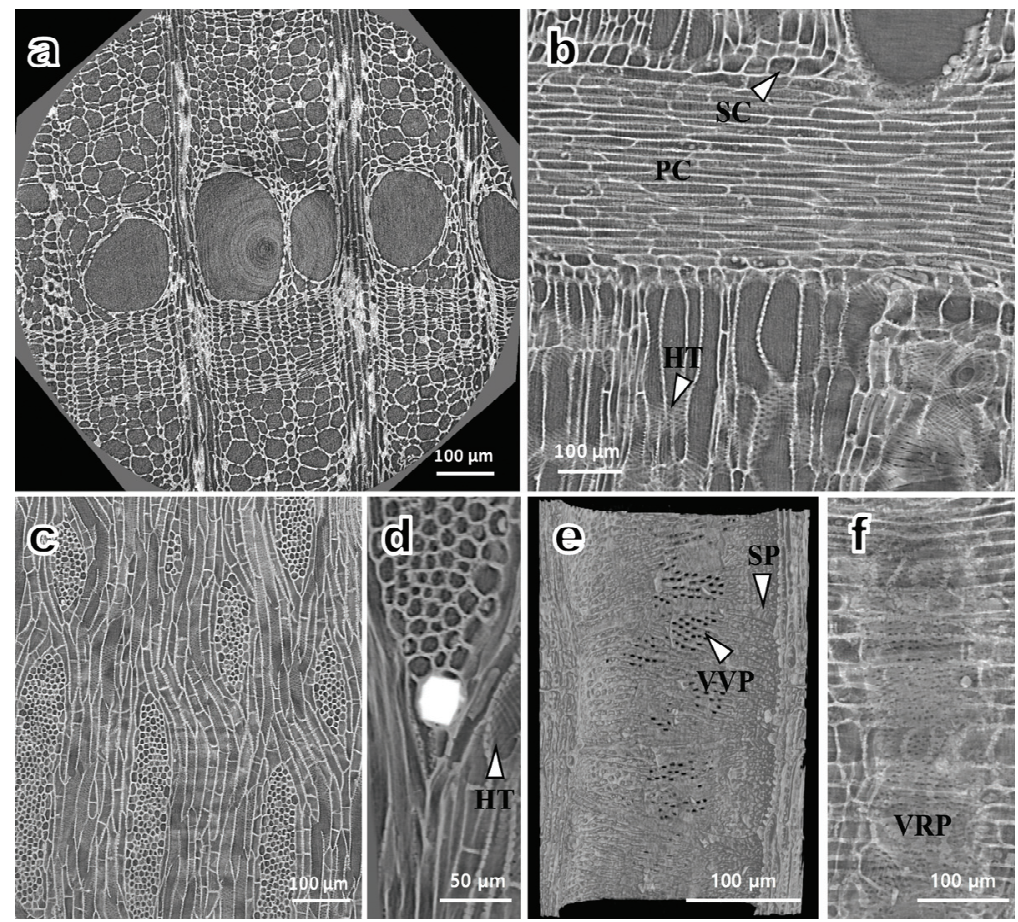

Fig. 2. Reconstructed images of the wood sample taken from the first column on the ground floor of Maseru pavilion. (a) Cross section; (b) radial section; (c) tangential section; (d) crystal in ray parenchyma cell; (e) intervessel pits; (f) vessel-ray pits. Note: SC, square cell; PC, procumbent cell; HT, helical thickening; $\mathrm{SP}$, simple perforation plate; VVP, vessel-vessel pitting; VRP, vessel-ray pitting. 
samples taken from the first column. The growth ring boundary was distinct and the vessel arrangement was ring-porous with diameters ranging from 85 to 165 micrometers (Fig. 2a). One thing to note here is that the concentric shapes observed in the centers of Figs. $2 \mathrm{a}$ and $3 \mathrm{a}$ are ring artifacts commonly encountered in computed tomography and are not derived from wood. Ring artifacts are caused by a variety of factors, including miscalibration, detector failure, or insufficient radiation dose in a CT scanner (Triche et al., 2019). In the radial section (Fig. 2b), the cellular composition of rays consisted of procumbent cells with a row of square marginal cells. In addition, helical thickenings were only present in narrower vessel elements. Multiseriate rays with 2-9 seriate were observed in the tangential section (Fig. 2c), and crystals existed in enlarged cells (Fig. 2d). The arrangement of intervessel pits and vessel-ray parenchyma pits were both alternate type (Fig. 2e and 2f). Simple perforation plates were observed in the images obtained by cutting the vessels parallel to the axial direction. All anatomical evidence observed from the images was consistent with the characteristics of Zelkova serrata.

Reconstructed images of the second column are shown in Fig. 3. The porosity of vessels seemed to be diffuse-porous with a radial pattern in the cross
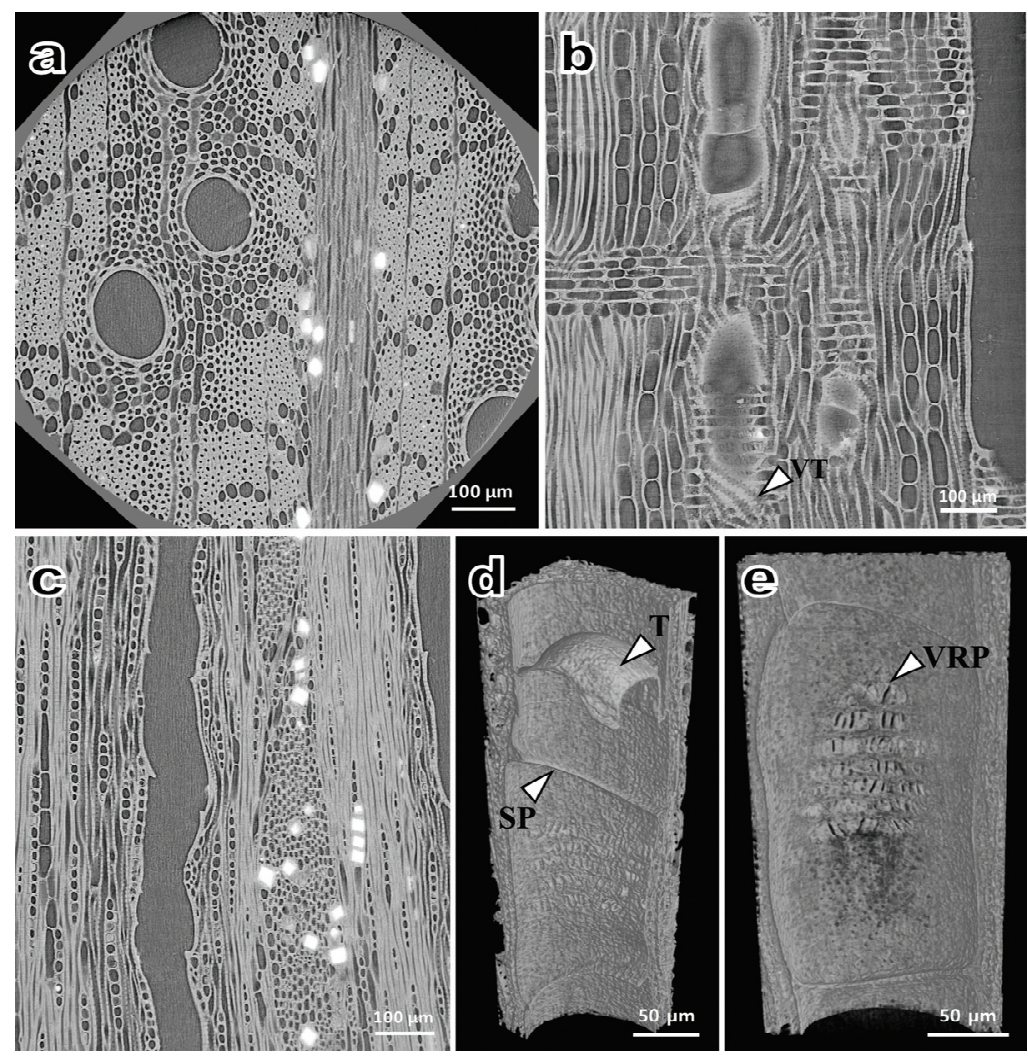

Fig. 3. Reconstructed images of the sample taken from the second column on the ground floor of Manseru pavilion. (a) Cross section; (b) radial section; (c) tangential section; (d) inner part of a vessel; (e) palisade type vessel-ray pits. Note: VT, vasicentric tracheid; T, tylosis; SP, simple perforation plate; VRP, vessel-ray pitting. 
Wood Identification of Historical Architecture in Korea by Synchrotron X-ray

Microtomography-Based Three-Dimensional Microstructural Imaging

section (Fig. 3a). Crystals were observed in some axial parenchyma cells. There were vasicentric tracheids around vessels in the radial section (Fig. 3b). In the tangential section (Fig. 3c), rays with two distinct sizes were observed. The uniseriate ray and the broad ray both contained crystals, and the cellular composition of rays were all procumbent cells. A tylosis and simple perforation plates were present in vessels (Fig. 3d). Furthermore, vessel-ray parenchyma pits were a vertically arranged palisade type (Fig. 3e). This is a genus specific feature of Quercus.

All the features observed in Fig. 3 suggest Quercus subg. Cyclobalanopsis (Noshiro and Sasaki, 2011; Kobayashi et al., 2019b). However, it is difficult to conclude that the porosity is diffuse porous with a radial pattern because the vessel arrangement in earlywood could not be observed in the cross section (Fig. 3a). Without considering wood porosity, all the features are also consistent with Quercus sect. Cerris. To determine the porosity of the sample, macroscopic visual inspection using a stereomicroscope was performed on other specimens taken from the same column. As a result, the sample was identified as a ring porous species owing to the presence of large earlywood vessels with tangential diameters greater than $200 \mu \mathrm{m}$ in a specimen. From these observations, we classified the sample as Quercus sect. Cerris.

\subsection{Beam and joist}

Fig. 4 presents the cross sections and rays of wood samples taken from the beam (Fig. $4 a$ and $4 b$ ) and joist (Fig. 4c and 4d). In the cross section of the beam (Fig. 4a), an axial resin canal with thin-walled epithelial cells and a gradual transition from earlywood to latewood were observed. Cross-field pits were windowlike type and ray tracheids were present in rays (Fig. 4b). These features can be observed in Pinus spp. among the native species in Korea.
$P$. densiflora and $P$. thunbergii in the subgenus Diploxylon, and $P$. koraiensis, $P$. pumila, and $P$. parviflora in the subgenus Haploxylon, are representative Pinus species in Korea. The key criterion for classification between the Diploxylon and Haploxylon species is the presence or absence of dentate thickening in the ray tracheid wall. The Diploxylon species have dentate thickenings in ray tracheids, but these are not observed in Haploxylon. In Fig. 4b, the ray tracheids had smooth walls without dentate. Therefore, it was considered that the samples are close to the Haploxylon species, and the gradual transition from earlywood to latewood is another piece of evidence for Haploxylon (Fig. 4a).

Among the Haploxylon species, $P$. pumila, which belongs to the subsection Cembrae together with $P$. koraiensis, is not used as a structural member owing its small size. The smooth end wall of the ray parenchyma cell observed in Fig. $4 \mathrm{~b}$ is an important key for distinguishing $P$. koraiensis from $P$. parviflora with distinctly pitted end walls (Eom, 2015). In addition, P. parviflora, a subsection Strobi, is a species only native to Ulleungdo Island, which is more than 200 $\mathrm{km}$ away, in a straight line, from Bongjeongsa temple, so it is very unlikely that the species was used in the construction of Manseru pavilion. For these reasons, the sample taken from the beam was judged to be $P$. koraiensis.

For the joist, there were no axial resin canals and axial parenchyma cells in the cross section (Fig. 4c). However, owing to the presence of window-like cross field pits and ray tracheids with a smooth wall in the radial section, this sample was also judged to be $P$. koraiensis.

From the wood identification of Manseru pavilion, two columns were identified as Zelkova serrata and Quercus spp., while both beam and joist were identified as Pinus koraiensis. At the time of the construction of Manseru pavilion (1680), the wood species identified in this study were commonly used to build Buddhist 

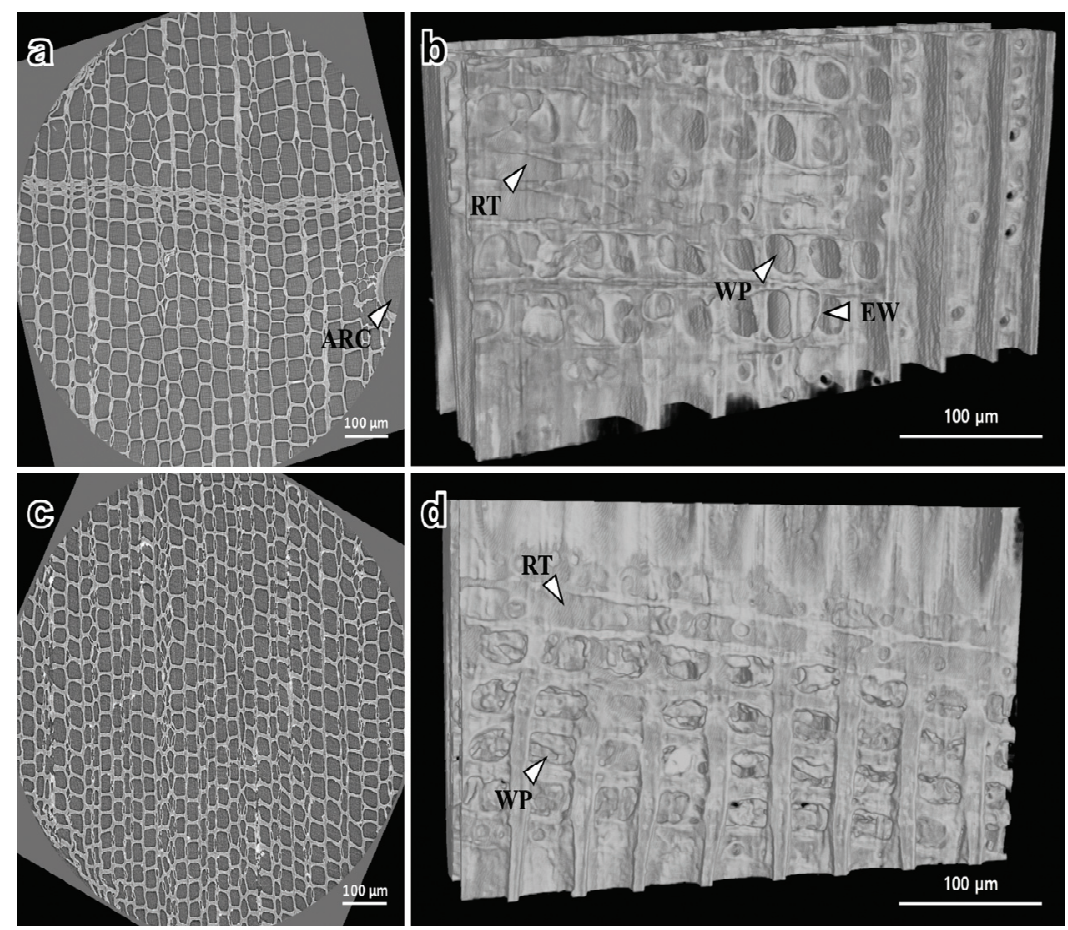

Fig. 4. Reconstructed images of the samples taken from the beam and joist of Manseru pavilion. Cross section (a) and ray cells (b) of the beam; cross section (c) and ray cells (d) of the joist. Note: ARC, axial resin canal; RT, ray tracheid; WP, window-like pit; EW, end wall of ray parenchyma cell.

temples (Park and Lee, 2007). One interesting point here is that Pinus species in Diploxylon was used for the columns of Geungnakjeon and Daeungjeon Halls, the other major buildings in Bongjeongsa temple (Park et al., 2005). Considering the fact that the logging of the Pinus trees was strictly controlled in the Joseon Dynasty, the difference in wood species may reflect a social aspect at the time they were built. During the Joseon Dynasty (13921897), when the Manseru pavilion was built, Buddhism was oppressed as Confucianism was a national ideology. In contrast, Buddhism was a national religion during the Goryeo Dynasty (918-1392), when the Geungnakjeon and Daeungjeon Halls were built, which are estimated to be the thirteenth and fourteenth centuries, respectively.

\section{CONCLUSION}

Using SR- $\mu \mathrm{CT}$, internal microstructures of wood samples that cannot be visualized by optical methods were reconstructed into three-dimensional images. The spatial resolution of this technique was sufficient to observe the major anatomical features of wood. The wood samples collected from the Manseru pavilion were identified as Zelkova serrata, Quercus sect. Cerris and Pinus koraiensis. The images reconstructed by SR- $\mu \mathrm{CT}$ are useful for obtaining various anatomical information owing to free manipulation such as cropping in various directions, extracting and modifying specific areas. There are many important wooden cultural properties that have not yet been identified owing to their managing specificity, especially for non-building wooden artifacts. 
Wood Identification of Historical Architecture in Korea by Synchrotron X-ray

Microtomography-Based Three-Dimensional Microstructural Imaging

SR- $\mu$ CT is an effective method of identifying such wooden artifacts with minimal damage. Furthermore, if there are naturally delaminated small wood fragments that commonly occur during the preservation process or storage of the artifacts, SR- $\mu \mathrm{CT}$ will not involve any further damage for wood identification.

\section{ACKNOWLEDGMENTS}

The synchrotron radiation experiment was performed at the BL20XU in the SPring-8 with the approval of the Japan Synchrotron Radiation Research Institute (JASRI) (Proposal No. 2016B1794). We thank Korea Forestry Promotion Institute (KOFPI) and Jung-Ae Oh, a senior researcher at the KOFPI, for providing the samples. We thank Edanz Group (www.edanzediting. com/ac) for editing a draft of this manuscript.

\section{REFERENCES}

Casali, F. 2006. X-ray and neutron digital radiography and computed tomography for cultural heritage. In: Bradley, B., Creagh, D. (Eds). Physical techniques in the study of art, archaeology and cultural heritage, Volume 1. Elsevier, Amsterdam.

Creagh, D. 2007. Synchrotron radiation and its use in art, archaeometry, and cultural heritage studies. In: Bradley, B., Creagh, D (Eds). Physical techniques in the study of art, archaeology and cultural heritage, Volume 2. Elsevier, Amsterdam.

Eom, Y.G. 2015. Wood anatomy of Korean species. MEDIA WOOD., Ltd. Seoul, Korea.

Eom, Y.J., Park, B.D. 2018. Wood species identification of documentary woodblocks of Songok clan of the Milseong Park, Gyeongju, Korea (in Korean). Journal of the Korean Wood Science and Technology 46(3): 270-277.

Kobayashi, K., Akada, M., Torigoe, T., Imazu, S., Sugiyama, J. 2015. Automated recognition of wood used in traditional Japanese sculptures by texture analysis of their low-resolution computed tomography data. Journal of Wood Science 61: 630-640.

Kobayashi, K., Hwang, S.W., Okochi, T., Lee, W.H., Sugiyama, J. 2019a. Non-destructive method for wood identification using conventional X-ray computed tomography data. Journal of Cultural Heritage 38: 88-93.

Kobayashi, K., Kegasa, T., Hwang, S.W., Sugiyama, J. 2019b. Anatomical features of Fagaceae wood statistically extracted by computer vision approaches: Some relationships with evolution. PLoS ONE 14(8): e0220762.

doi:10.1371/journal.pone.0220762.

Lee, G.H., Seo, J.W., Han, G.S. 2018. Dating wooden artifacts excavated at Imdang-dong site, Gyeongsan, Korea and interpreting the paleoenvironment according to the wood identification (in Korean). Journal of the Korean Wood Science and Technology 46(3): 241-252.

Mizuno, S., Torizu, R., Sugiyama, J. 2010. Wood identification of a wooden mask using synchrotron X-ray microtomography. Journal of Archaeological Science 37: 2842-2845.

Noshiro, S., Sasaki, Y. 2011. Identification of Japanese species of evergreen Quercus and Lithocarpus (Fagaceae). IAWA Journal 32(3): 383-393.

Park, B.S., Chong, S.H., Chung, D.J., Seo, J.W. 2005. Species composition of major wooden cultural properties (in Korean). Korea Forest Research Institute, Seoul, Korea. pp. 43-54.

Park, J.H., Oh, J.E., Hwang, I.S., Jang, H.U., Choi, J.W., Kim, S.C. 2018. Study on species identification for Pungnammun Gate (Treasure 308) in Jeonju, Korea (in Korean). Journal of the Korean Wood Science and Technology 46(3): 278-284.

Park, W.K., Lee, K.H. 2007. Changes in the species of woods used for Korean ancient and historic architectures (in Korean). Journal of Architectural 
History 16: 9-28.

Steppe, K., Cnudde, V., Girard, C., Lemeur, R., Cnudde, J.P., Jacobs, P. 2004. Use of X-ray computed microtomography for non-invasive determination of wood anatomical characteristics. Journal of Structural Biology 148(1): 11-21.

Suzuki, Y., Uesugi, K., Takimoto, N., Fukui, T., Aoyama, K., Takeuchi, A., Takano, H., Yagi, N., Mochizuki, T., Goto, S., Takeshita, K., Takahashi, S., Ohashi, H., Furukawa, Y., Ohata, T., Matsushita, T., Ishizawa, Y., Yamazaki, H., Yabashi, M., Tanaka, T., Kitamura, H., Ishikawa, T. 2004. Construction and commissioning of A $248 \mathrm{~m}$-long beamline with X-ray undulator light source. In: Warwick, T., Arthur, J., Padmore, H.A., Stöhr, J (Eds). Synchrotron radiation instrumentation: Eighth international conference on synchrotron radiation instrumentation. American Institute of Physics, College Park.

Tazuru, S., Sugiyama, J. 2019. Wood identification of Japanese Shinto deity statues in Matsunootaisha Shrine in Kyoto by synchrotron X-ray microtomography and conventional microscopy methods. Journal of Wood Science 65(1): 1-7.

Triche, B.L., Nelson Jr, J.T., McGill, N.S., Porter, K.K., Sanyal, R., Tessler, F.N., McConathy, J.E., Gauntt, D.M., Yester, M.V., Singh, S.P. 2019. Recognizing and minimizing artifacts at CT, MRI, US, and molecular imaging. RadioGraphics 39(4): 1017-1018.

Van den Bulcke, J., Boone, M., Van Acker, J., Stevens, M., Van Hoorebeke, L. 2009. X-ray tomography as a tool for detailed anatomical analysis. Annals of Forest Science 66(5): 1-12. 